\title{
Pilot study of intratumoral injection of recombinant heat shock protein 70 in the treatment of malignant brain tumors in children
}

\author{
Maxim A Shevtsov ${ }^{1,2}$ \\ Alexander $\mathrm{V} \mathrm{Kim}^{2}$ \\ Konstantin A \\ Samochernych ${ }^{2}$ \\ Irina V Romanova ${ }^{3}$ \\ Boris A Margulis' \\ Irina $\vee$ Guzhova' \\ Igor V Yakovenko \\ Alexander M Ischenko ${ }^{4}$ \\ William A Khachatryan ${ }^{2}$ \\ 'Institute of Cytology of the Russian \\ Academy of Sciences, ${ }^{2} \mathrm{AL}$ Polenov \\ Russian Research Scientific \\ Institute of Neurosurgery, ${ }^{3} \mathrm{MM}$ \\ Sechenov Institute of Evolutionary \\ Physiology and Biochemistry of \\ the Russian Academy of Sciences, \\ ${ }^{4}$ Research Institute of Highly Pure \\ Biopreparations, St Petersburg, \\ Russian Federation
}

This article was published in the following Dove Press journal:

OncoTargets and Therapy

18 June 2014

Number of times this article has been viewed

\begin{abstract}
Intratumoral injections of recombinant heat shock protein (Hsp)70 were explored for feasibility in patients with brain tumors. Patients aged 4.5-14 years with untreated newly diagnosed tumors $(n=12)$ were enrolled. After tumor resection, five injections of recombinant Hsp70 (total $2.5 \mathrm{mg}$ ) were administered into the resection cavity through a catheter. Before administration of Hsp70 and after the last injection, specific immune responses to the autologous tumor lysate were evaluated using the delayed-type hypersensitivity test. Further, peripheral blood was monitored to identify possible changes in lymphocyte subpopulations, cytokine levels, and the cytolytic activity of natural killer cells. The follow-up period in this trial was 12 months. Intratumoral injections of Hsp70 were well tolerated by patients. One patient had a complete clinical response documented by radiologic findings and one patient had a partial response. A positive delayed-type hypersensitivity test was observed in three patients. In peripheral blood, there was a shift from cytokines provided by $\mathrm{Th}_{2}$ cells toward cytokines of a $\mathrm{Th}_{1}$-cell-mediated response. These data corresponded to changes in lymphocyte subpopulations. Immunosuppressive T-regulatory cell levels were also reduced after injection of Hsp70, as well as production of interleukin-10. The cytolytic activity of natural killer cells was unchanged. The present study demonstrates the feasibility of intratumoral delivery of recombinant $\mathrm{Hsp} 70$ in patients with cancer. Further randomized clinical trials are recommended to assess the optimum dose of the chaperone, the treatment schedule, and clinical efficacy.
\end{abstract}

Keywords: heat shock protein 70 , malignant brain tumors, immunotherapy, glioblastoma

\section{Introduction}

Primary malignant brain tumors are the second most common pediatric malignancies after leukemia, representing $20 \%$ of all cancers in children. In the majority of cases, treatment consists of surgery followed by radiotherapy and concomitant chemotherapy. ${ }^{1}$ Despite this aggressive multimodal approach, the prognosis for patients is poor. Among the new treatments currently being investigated, immunotherapy is theoretically very attractive because it offers the potential for highly tumor-specific effects. ${ }^{2}$ In recent years, evidence has accumulated for the potential immunotherapeutic anticancer activity of the molecular chaperone, heat shock protein (Hsp)70. ${ }^{3}$ The immunologic function of Hsps was first discovered because of their ability to induce tumor rejection when they were purified from the tumor. ${ }^{4}$ Later it was shown that tumor-derived Hsps can carry cancer-associated peptides as cargo into antigen-presenting cells for subsequent presentation with major histocompatibility complex class I to CD8+ (cluster of differentiation 8) T-lymphocytes, triggering formation of subpopulations of tumor-specific effector cells. ${ }^{5}$ This
Correspondence: Maxim A Shevtsov AL Polenov Russian Research Scientific Institute of Neurosurgery, 191104 Mayakovsky Str 12,

St Petersburg, Russian Federation

$\mathrm{Tel}+78 \mid 22738196$

Fax +78I 22739308

Email shevtsov-max@mail.ru 
hypothesis was investigated in several clinical trials where autologous tumor-derived Hsps were used as vaccines in patients with cancers at various locations. ${ }^{6-8}$

Recently, much attention has focused on the peptideindependent immunomodulatory activity of chaperones. It has been shown that Hsps can move into the extracellular space encased in exosomes or in soluble form, where they function as natural adjuvants, enhancing innate and adaptive immune responses. ${ }^{9,10}$ By binding specific receptors, ie, Toll-like receptor (TLR)-2 and TLR-4, they induce expression of costimulatory molecules, maturation of dendritic cells, and secretion of proinflammatory cytokines, eg, tumor necrosis factor-alpha (TNF- $\alpha$ ), interleukin (IL)-1 $\beta$, IL-12, IL-6, and granulocyte-macrophage colonystimulating factor. ${ }^{11,12}$ Moreover, Hsp70 can activate the cytolytic and migratory activity of natural killer cells. ${ }^{13}$ Since Hsps modulate the immune system toward a cellmediated response, they could be useful in approaches to the treatment of cancer.

Previously we have demonstrated the immunomodulatory antitumor activity of Hsp70 in models of B16 melanoma, RA-2 rhabdomyosarcoma, and C6 glioblastoma, ${ }^{14-16}$ and intratumoral injection of recombinant Hsp70 was demonstrated to be therapeutically relevant in the treatment of C6 rat glioblastoma. ${ }^{15}$ Infusion of Hsp70 delayed the rate of tumor growth and prolonged survival in tumor-bearing rats. Therapeutic efficacy was accompanied by enhanced antitumor activity of natural killer cells (production of granzyme B) as well as CD8+ cytotoxic T-lymphocytes, as shown by interferon-gamma (IFN- $\gamma$ ) ELISPOT (enzymelinked immunospot) assay. ${ }^{15}$ In a recent in vitro study, we further explored the possible antitumor immunomodulatory mechanism of Hsp70 activity, ${ }^{17}$ and demonstrated that exogenously delivered Hsp70 penetrated cancer cells and induced translocation of its endogenous analog to the cell surface. This process significantly increased the sensitivity of tumor cells toward the cytolytic activity of lymphocytes. ${ }^{17}$

Following in vitro and in vivo assessments of Hsp70 activity, we investigated the feasibility, safety, side effects, and immunologic responses associated with Hsp70 therapy in pediatric patients with malignant brain tumors.

\section{Materials and methods Clinical study design}

Patients of both sexes with newly diagnosed malignant brain tumors without any previous treatment were enrolled in the study (Table 1). The study protocol stipulated that tumor resections be as complete as believed safely feasible by the surgeons. All resections were done by two designated study surgeons in a neurosurgical institution. Surgery was done using a neurosurgical microscope (Carl Zeiss Surgical $\mathrm{GmbH}$, Oberkochen, Germany). Other intraoperative diagnostic procedures (eg, sonography, neuronavigation) were performed for planning of the surgical approach and for tumor localization. During tumor resection, a silicone catheter was implanted into the resection cavity. Following surgery, a course of five injections of Hsp70 were delivered into the resection cavity through the catheter, ie, $500 \mu \mathrm{g}$ of Hsp70 in saline solution was infused per single injection on days $1,3,5,7$, and 9 following surgery, for a total of $2.5 \mathrm{mg}$ of protein per course. Immunologic changes (lymphocyte subpopulations, cytokine levels, delayed-type hypersensitivity test for antitumor immune reaction) were monitored before and after the course of Hsp70 infusions. The patients

Table I Patient characteristics

\begin{tabular}{|c|c|c|c|c|c|c|}
\hline Case & Age & Gender & Histopathology & KPS & $\begin{array}{l}\text { Previous } \\
\text { treatment }\end{array}$ & Surgery \\
\hline I & 13 & M & Glioblastoma multiforme & 60 & _- & IR \\
\hline 2 & 13 & $M$ & Anaplastic astrocytoma (G III) & 80 & - & IR \\
\hline 3 & 7 & $M$ & Anaplastic ependymoma (G III) & 80 & - & IR \\
\hline 4 & 13 & M & B-cell non-Hodgkin's lymphoma & 80 & _ & IR \\
\hline 5 & 4 & M & Choroid plexus carcinoma (G IV) & 70 & _ & IR \\
\hline $6^{*}$ & 12 & $\mathrm{~F}$ & Primitive neuroectodermal tumor & 60 & $S$ & IR \\
\hline 7 & 10 & $\mathrm{~F}$ & Anaplastic astrocytoma (G III) & 80 & - & IR \\
\hline 8 & 14 & $\mathrm{~F}$ & Anaplastic ependymoma (G III) & 80 & - & IR \\
\hline $9 *$ & 12 & $M$ & Astrocytoma (G II) & 60 & $\bar{S}$ & IR \\
\hline 10 & 4,5 & $\mathrm{~F}$ & Astrocytoma (G II) & 70 & _ & IR \\
\hline 11 & 6 & $\mathrm{~F}$ & Anaplastic astrocytoma (G III) & 60 & _ & IR \\
\hline $12 *$ & 10 & $M$ & Glioblastoma multiforme & 60 & $\bar{s}$ & IR \\
\hline
\end{tabular}

Notes: *Patients 6, 9, and 12 had undergone ventriculoperitoneal shunting surgery. Patients did not receive any conventional treatment before the course of heat shock protein 70. Within 24 hours after surgery, the residual tumor was assessed by postoperative magnetic resonance imaging. Abbreviations: KPS, Karnofsky performance status; S, surgery; IR, incomplete resection; G, grade. 
received no other treatment except for corticosteroid therapy during the Hsp70 infusions. Pretreatment with dexamethasone $4 \mathrm{mg}$ (from various manufacturers) twice daily was given for at least 2 days before surgery and continued for 5 days thereafter. For evaluation of the short-term response of the tumor to chaperone treatment with Hsp70, magnetic resonance imaging (MRI) was performed in the 24 hours following surgery and again 4 weeks after the final Hsp70 infusion. All patients were monitored for adverse events. The follow-up period for the study was 12 months. Following the course of chaperone treatment, patients received conventional radiotherapy or chemotherapy.

\section{Eligibility}

Patients of both sexes with newly diagnosed malignant brain tumors and whose parents provided written informed consent according to a resolution of the local ethics committee of the AL Polenov Russian Research Scientific Institute of Neurosurgery (St Petersburg, Russian Federation) were eligible for this study. Inclusion criteria were: intraoperative histologically proven diagnosis of malignant brain tumor on review by two independent pathologists; 3-18 years of age; Karnofsky performance status $>60$; absolute neutrophil count (neutrophils and bands) $\geq 1.5 \times 10^{9} / \mathrm{L}$; platelets $\geq 100 \times 10^{9} / \mathrm{L}$; aspartate aminotransferase or alanine aminotransferase $\leq 5$ times the upper limit of normal, total bilirubin $\leq 1.5$ times the upper limit of normal, serum creatinine $\leq 1.5$ times the upper limit of normal, or estimated creatinine clearance $\geq 60 \mathrm{~mL}$ per minute; no known immunosuppression; negative human immunodeficiency virus serology; no evidence of acute or chronic hepatitis on standard hepatitis C and B screening tests; no second malignancies; absence of active infection; no history or clinical evidence of active autoimmune disease; informed consent by parents. Exclusion criteria were: not proven diagnosis of malignant brain tumor by the biopsy during the operation of malignant brain tumor after surgical resection; concomitant life-threatening disease; presence of acute (including respiratory) infection; known immunosuppressive disease; positive serology for human immunodeficiency virus, hepatitis B or C; history of an autoimmune disease; history of other malignancies; psychologic, family, sociologic, or geographic conditions not permitting adequate medical follow-up; and compliance with the study protocol.

\section{Preparation of recombinant human Hsp70}

Recombinant Hsp70 was produced in the Research Institute of Highly Pure Biopreparations (St Petersburg, Russian
Federation) from Escherichia coli transformed with a pMSHsp70 (plasmid maintenance sequence heat shock protein 70) plasmid according to Good Manufacturing Practice standards. ${ }^{18,19}$ Briefly, Hsp70 was purified by anion exchange chromatography using DEAE-Sepharose (GE Healthcare Life Sciences, Cleveland, OH, USA) followed by adenosine triphosphate (ATP)-affinity chromatography on ATP-agarose (Sigma, St Louis, MO, USA). Endotoxin was depleted by polymyxin B-sepharose endotoxin-removing gel (Sigma). Quantitation of endotoxin was performed using the Limulus amoebocyte lysate assay (QCL-1000; Cambrex Bio Science, Walkersville, MD, USA). The resulting endotoxin content was below $0.1 \mathrm{EU} / \mathrm{mg}$ Hsp70. To confirm that the immunomodulatory activity of Hsp70 was not due to endotoxin contamination, we boiled $\mathrm{Hsp} 70$ (at $95^{\circ} \mathrm{C}$ ) and assessed its activity in a series of in vitro tests as described previously (ie, activation of lymphocytes in the cytotoxic T-lymphocyte test). ${ }^{15}$ The results demonstrated that the heated preparation of Hsp70 had no immunostimulatory activity. Protein concentration was measured using the Bradford protein assay (Bio-Rad Laboratories Inc., Hercules, CA, USA) and purity was determined by sodium dodecyl sulfate polyacrylamide gel electrophoresis.

\section{Evaluation of clinical status}

The toxicity of Hsp70 was monitored and graded according to the National Cancer Institute Common Terminology Criteria for Adverse Events version 3.0. ${ }^{20}$ Immediate and delayed toxicities were assessed following each delivery of Hsp70 solution. Evaluation of autoimmune symptoms and neurologic examinations were done before and 30 minutes after vaccination, and at all 4-weekly follow-up visits. MRI was done to monitor intracranial lesions after treatment with Hsp70. MRI scans were performed preoperatively and within 24 hours after surgery (before the course of Hsp70). The presence of residual tumor was assessed by postoperative MRI. Residual tumor was defined as contrast enhancement with a volume $>0.175 \mathrm{~cm}^{3}$. The cutoff volume represented the size of one voxel in the $\mathrm{T} 1 \mathrm{image}$ and corresponded to the minimal resolution obtained on MRI. The cutoff volume was defined to prevent interpretation problems when distinguishing between tumor and nonspecific enhancement. The volumes of residual tumors were segmented on individual scans, and the individual volumes were summed for the final volume. All patients were divided into groups of complete or incomplete resection whether or not they had a contrast-enhancing lesion. Four weeks after the last intratumoral injection of Hsp70, we performed MRI for assessment of tumor responses to 
chaperone therapy. Clinical responses were classified based on the criteria devised by Macdonald et al: ${ }^{21}$ complete response, defined as complete disappearance of the tumor for at least 4 weeks; partial response, defined as a reduction of $50 \%$ or more in tumor size for at least 4 weeks; minor response, defined as a $25 \%-50 \%$ decrease in size of the lesion lasting at least 4 weeks or a more than $50 \%$ decrease in lesion size lasting less than 4 weeks; stable disease, defined as either a decrease of less than $25 \%$ or an increase of less than $25 \%$ in tumor size for at least 4 weeks; and progressive disease, defined as an increase of $25 \%$ or more in tumor size.

\section{Immunofluorescence analyses of Hsp70 expression in tumor samples}

Hsp70 was analyzed in tumor biopsies obtained from all patients during surgery. Serial frozen sections of biopsy specimens were cut at a thickness of $7 \mu \mathrm{m}$ and stained with monoclonal anti-Hsp70 antibodies (clone BRM-22; Sigma) and secondary goat anti-mouse Alex568 conjugated antibodies (Thermo Fisher Scientific, Waltham, MA, USA). The nucleus was detected using 4',6-diamidino-2-phenylindole. Monoclonal anti-Hsp70 antibody reacts specifically against inducible (Hsp72) and constitutive (Hsp73) forms of Hsp70. Mouse immunoglobulin G1 isotype antibodies were used as the control. Sections were mounted using DAKO fluorescent mounting medium (Dako North America Inc., Carpinteria, CA, USA). Fluorescence images were captured with a Leica TCS SP5 confocal system, equipped with lasers exciting at $543 \mathrm{~nm}(\mathrm{He} / \mathrm{Ne})$ and $405 \mathrm{~nm}$ (diode laser) on a Leica DM IRBE microscope stand with an HCX PL APO 100×1.40 NA, HP $40 \times 1.25$ oil immersion objective lens (Leica Microsystems, Heidelberg, Germany).

\section{Evaluation of immunologic status Delayed-type hypersensitivity test}

A mixture of $0.05 \mu \mathrm{g}$ of purified tuberculin and $10 \mu \mathrm{g}$ of autologous tumor lysate was administered intradermally into the forearm before and after 1 month of treatment ${ }^{22}$ to evaluate the specific cell-mediated immune response in the treated patients. A positive delayed-type hypersensitivity skin test reaction was defined as $>2 \mathrm{~mm}$ diameter induration after 48 hours.

\section{Cytotoxic T-lymphocyte test}

For the cytotoxic T-lymphocyte test, peripheral blood lymphocytes were obtained after tumor resection and again 2 weeks after the last intratumoral infusion of Hsp70. Peripheral blood lymphocytes were isolated by Histopaque ${ }^{\circledR} 1.077$ (Sigma) gradient centrifugation. Cell viability was determined by $0.4 \%$ trypan blue exclusion before the experiments. Lymphocytes were challenged with K562 (human erythroleukemia) cells as target cells for analysis of the cytolytic activity of the natural killer cells obtained. Prior to the cytotoxic assay, the K562 cells were labeled with $5 \mu \mathrm{M}$ CellTracker Orange CMTMR (Thermo Fisher Scientific). They were then added to the effector cells (peripheral blood lymphocytes) at different effector to target cell ratios of 12.5:1, 25:1, and 50:1 and incubated for 4 hours. A fluorescent compound 7-amino-actinomycin D (BD Biosciences, San Jose, CA, USA) was added to each tube at a final concentration of $1 \mu \mathrm{g} / \mathrm{mL}$, as recommended by the manufacturer. The stained samples were analyzed by multicolor flow cytometry immediately after the end of the incubation period. Cytotoxicity was calculated as the percentage of CellTracker Orange CMTMR+, 7-amino-actinomycin D+ cells of the total CellTracker Orange CMTMR+ cells.

\section{Cell surface analyses}

To assess possible changes in lymphocytes and their subpopulations before and after administration of Hsp70, peripheral blood lymphocytes were collected from the patients, resuspended in phosphate-buffered saline containing $1 \%$ bovine serum albumin and $0.1 \%$ sodium azide (Sigma), and stained with monoclonal antibodies against human CD3, CD4, CD8, CD19, CD25, CD56, or HLA (human leukocyte antigen) DR for 30 minutes at $4^{\circ} \mathrm{C}$. T-regulatory cells were detected as CD4+CD25+FoxP3+ cells. For intracellular staining for FoxP3+, we applied anti-FoxP3 antibodies (R\&D Systems Inc., Minneapolis, MN, USA). The stained cells were then washed and analyzed using FACScan (Becton Dickinson, San Jose, CA, USA). Species-matched and isotype-matched monoclonal antibodies were used as controls.

\section{Detection and quantification of cytokines}

Quantification of IL-1 $\beta$, IL-1Ra, IL-2, IL-4, IL-6, IL-10, IFN- $\gamma$, and TNF- $\alpha$ in serum (or cerebrospinal fluid) and culture supernatants of stimulated lymphocytes was performed using commercially available enzyme-linked immunosorbent assay kits (eBiosciences, San Diego, CA, USA), in accordance with the manufacturer's instructions. For stimulation, peripheral blood lymphocytes were treated with phytohemagglutinin (Biological Industries, Beit HaEmek, Israel) at a concentration of $20 \mathrm{mg} / \mathrm{mL}$ for 48 hours.

\section{Statistical analysis}

Continuous variables were compared using the paired Student's $t$-test. Statistical significance was determined at the 
$P<0.05$ level. The two-tailed Mann-Whitney log-rank test was used to compare the study and control groups.

\section{Results \\ Patient characteristics}

Twelve patients were enrolled in the pilot study (Table 1) and comprised five girls and seven boys of mean age 9.9 (4.5-14) years. A histologic diagnosis of malignant brain tumor on intraoperative biopsy was the key criterion for inclusion in the study. On subsequent evaluation of paraffin block sections (when administration of Hsp70 was performed), different histologic types of malignant tumors were identified. All biopsy material was checked for the presence of Hsp70 by immunofluorescence analysis. As expected, we observed marked expression of cytoplasmic Hsp70 in all 12 patients. Three patients (cases 6, 9, and 12) had previously undergone surgery (ventriculoperitoneal shunting) at the AL Polenov Russian Research Scientific Institute of Neurosurgery before participating in the study. All patients were treated before and after surgery with corticosteroids in standard doses. Starting on the day following tumor debulking, all patients received a series of injections of purified chaperone Hsp70 through a silicone catheter implanted in the resection cavity. The total amount of infused protein was $2.5 \mathrm{mg}$ (500 $\mu \mathrm{g}$ per injection). Evaluations for toxicity and treatment response were conducted from the first day of administration of Hsp70. All patients had baseline MRIs within 24 hours of tumor resection before starting infusion of Hsp70. According to their postoperative MRIs, all 12 patients had a residual contrastenhancing lesion related to incomplete resection.

\section{Assessment of safety and clinical responses}

Intratumoral infusions of purified chaperone Hsp70 were well tolerated, except in three patients (cases 5, 6, and 10) in whom major (grade 3 ) adverse effects were observed (Table 2). Five patients had grade 2 fever, three patients had grade 3 headaches, three further patients had grade 2 headaches, and one patient each had grade 1 and grade 2 vomiting. In seven patients, clinical symptoms started to appear 1.5-2 hours after each chaperone injection and abated in 5-6 hours to a normal level. There were no treatment-related hematologic, hepatic, or renal toxicities, nor any clinical or radiologic signs of autoimmune reactions in any patient.

The radiologic criteria devised by Macdonald et $\mathrm{al}^{21}$ were used to evaluate the clinical responses to intratumoral infusion of Hsp70. ${ }^{21}$ Four weeks after the last injection of Hsp70, nine patients showed no change on MRI scan (stable disease); one patient (case 7) showed a complete response; one patient (case 5) showed a partial response (Figure 1); and one patient (case 12) showed disease progression (Table 2). The MRI of one patient (case 7) showed no signs of the contrast enhancement lesion 4 weeks after the final administration of chaperone Hsp70.

Antitumor cell-mediated responses were analyzed in all patients following assessment of the MRI scans. For this purpose, purified tuberculin with autologous tumor lysate was administered into the forearm before and after Hsp70 injection. ${ }^{22}$ The test was positive in only three patients, including the patient with a clinical complete response (case 7), and was negative in nine patients. Eleven patients

Table 2 Results of administration of heat shock protein 70

\begin{tabular}{|c|c|c|c|c|c|}
\hline Case & $\begin{array}{l}\text { Total amount of } \\
\text { injected protein }(\mathrm{mg})\end{array}$ & $\begin{array}{l}\text { Radiologic } \\
\text { response }\end{array}$ & DTH & Adverse effects & Outcome \\
\hline I & 2.5 & SD & Positive & Fever (grade 2) & Alive \\
\hline 2 & 2.5 & SD & Negative & No & Alive \\
\hline 3 & 2.5 & SD & Negative & No & Alive \\
\hline 4 & 2.5 & SD & Negative & No & Alive \\
\hline 5 & 2.5 & PR & Positive & $\begin{array}{l}\text { Fever (grade } 2 \text { ), headache (grade } 3 \text { ), } \\
\text { vomiting (grade } 2 \text { ) }\end{array}$ & Alive \\
\hline 6 & 2.5 & SD & Negative & Fever (grade 2), headache (grade 3) & Alive \\
\hline 7 & 2.5 & CR & Positive & Fever (grade 2), headache (grade 2) & Alive \\
\hline 8 & 2.5 & SD & Negative & Fever (grade 2), headache (grade 2) & Alive \\
\hline 9 & 2.5 & SD & Negative & Headache (grade 2) & Alive \\
\hline 10 & 2.5 & SD & Negative & $\begin{array}{l}\text { Fever (grade } 2 \text { ), headache (grade } 3 \text { ), } \\
\text { vomiting (grade I) }\end{array}$ & Alive \\
\hline II & 2.5 & SD & Negative & No & Alive \\
\hline 12 & 2.5 & PD & Negative & No & Dead \\
\hline
\end{tabular}

Notes: Before the course of heat shock protein 70, all patients had baseline MRI. Four weeks after the last intratumoral infusion of heat shock protein, the tumor was assessed on MRI and clinical responses were classified based on the criteria of Macdonald et al. ${ }^{21}$ The follow-up period was 12 months.

Abbreviations: DTH, delayed-type hypersensitivity test; SD, stable disease; CR, complete response; PR, partial response; PD, progressive disease; MRI, magnetic resonance imaging. 
A
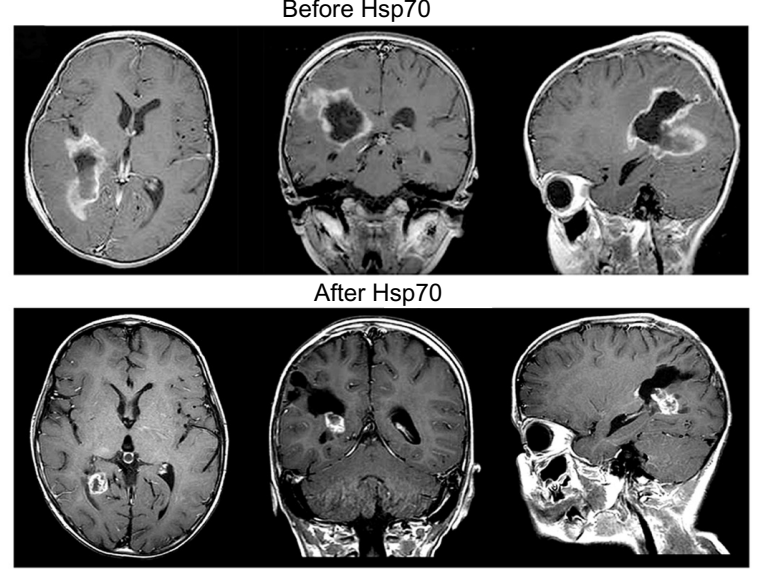

B

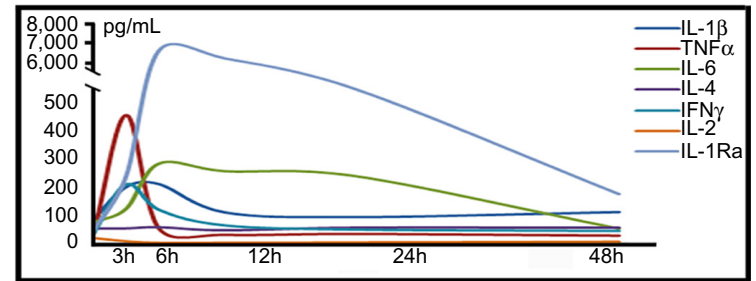

C

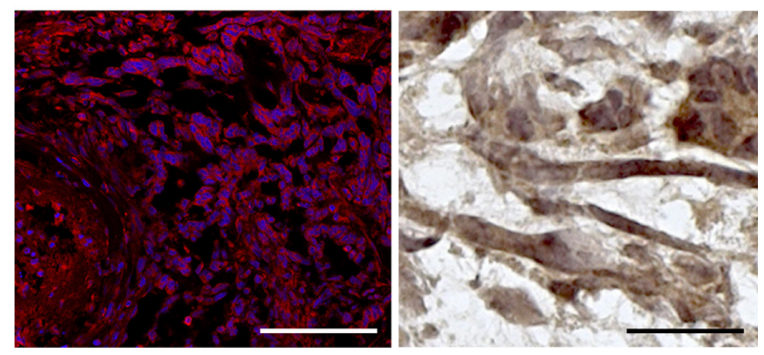

Figure I Case report of intratumoral Hsp70 therapy in patient 5.

Notes: (A) MRI brain images in a 4-year-old boy with a choroid plexus carcinoma before intratumoral injections of Hsp70 (upper panels) with MRI 4 weeks after the last intralesional infusion of Hsp70. (B) Analysis of cytokine (IL-I $\beta$, IL-IRa, IL-2, IL-4, IL-6, interferon-gamma, tumor necrosis factor-alpha) levels in cerebrospinal fluid after a single Hsp70 infusion. Cerebrospinal fluid was collected 3, 6, 12, 24 and 48 hours after injection of chaperone and cytokines were detected by enzyme-linked immunosorbent assay. (C) Immunofluoresence image of choroid plexus carcinoma section, with $\mathrm{Hsp} 70$ detected by monoclonal antibodies BRM-22a (with Alexa568 conjugated secondary antibodies, red color). Nuclei were stained by DAPI (blue color). Scale bar, $75 \mu \mathrm{m}$. On the right is a magnified image of tumor cells on the immunohistochemistry assay with BRM-22a antibodies to $\mathrm{Hsp} 70$ revealed by standard biotin-peroxidase reaction (nuclei stained by hematoxylin). Scale bar, $10 \mu \mathrm{m}$.

Abbreviations: h, hours; Hsp70, heat shock protein 70; TNF $\alpha$, tumor necrosis factor alpha; IL-I Ra, interleukin-I receptor antagonist; IFN $\gamma$, interferon gamma; DAPI, 4',6-diamidino-2-phenylindole; IL, interleukin; MRI, magnetic resonance imaging.

were alive and the patient who progressed had died by the end of the follow-up period.

\section{Local administration of Hsp70 leads to a T helper (Th),-polarizing immune response} It has been demonstrated previously that the peptideindependent chaperone Hsp70 has important cytokine activity, the main function of which could be summarized as polarizing the immune system toward a T-cell mediated response. ${ }^{10}$ To assess this hypothesis, the numbers of immune cells in peripheral blood were evaluated before and after administration of Hsp70. Using monoclonal antibodies, the numbers of distinct lymphocyte subpopulations in peripheral blood were analyzed on the first day after tumor resection and again 1 week after the last Hsp70 injection (Table 3). The relative level of each lymphocyte subpopulation was assessed in comparison with that of total lymphocytes. The levels of each individual cell type immediately after resection were used as controls, so that the immune condition before Hsp70 administration was a reference point for evaluation of immunologic changes during treatment. An increase in relative content of T-lymphocytes after Hsp70 infusion (including CD4+, CD8+) was observed in all 12 patients. Intriguingly, an increase in the relative proportion of the activated CD3+HLA DR+ cell population (from $2.3 \% \pm 0.5 \%$ to $4.8 \% \pm 0.6 \%, P<0.001$ ) was observed. Parallel to the increase in T-cell level, there was a statistically significant decrease in the relative proportion of B-lymphocytes (CD19+) from $27.3 \% \pm 2.3 \%$ to $16.8 \% \pm 2.0 \%$ $(P<0.001)$. The observed change in the relative proportions of T-cell and B-cell populations could be due to the influence of Hsp70. Cytokine (IL-4, IL-6, IFN- $\gamma$, TNF- $\alpha$ ) levels were measured in order to evaluate the immune system function better. It is already well known that IL-4 and IL-6 are predominantly produced by $\mathrm{Th}_{2}$ cells and B-cells and are responsible for humoral immunity, whereas IFN- $\gamma$ and TNF- $\alpha$ are secreted by $\mathrm{Th}_{1}$-helper cells and CD8+ T-cells and are responsible for cell-mediated immunity. These cytokines have opposing functions. The above-mentioned cytokine levels were measured in serum, along with their spontaneous and induced (by phytohemagglutinin) levels of production by peripheral blood lymphocytes in medium (Table 4). As expected, a dramatic decrease in IL-4 and IL- 6 cytokines was observed in serum, whereas IFN- $\gamma$ and TNF- $\alpha$ levels were elevated two-fold. These changes in serum cytokine levels were reflected in their spontaneous production in vitro. IL-4 and IL-6 levels in medium abated, while spontaneous production of IFN- $\gamma$ and TNF- $\alpha$ was elevated. Analysis of induced cytokine production also revealed the same tendency, ie, decreases in IL-4 and IL-6 along with elevations in IFN- $\gamma$ (from $344.2 \pm 111.9 \mathrm{pg} / \mathrm{mL}$ to $862.9 \pm 283.0 \mathrm{pg} / \mathrm{mL}$ ) and TNF- $\alpha$ (from $66.4 \pm 17.5 \mathrm{pg} / \mathrm{mL}$ to $225.3 \pm 47.9 \mathrm{pg} / \mathrm{mL}$ ). These data provide evidence that there was a shift toward T-cellmediated responses maintained by $\mathrm{Th}_{1}$-helper cells (production of IFN- $\gamma$ and TNF- $\alpha$ ) after administration of Hsp70.

An elevation in temperature was observed in six patients immediately after intratumoral injection of Hsp 70 (1.5-2 hours). The peak of the temperature curve (up to $38.5^{\circ} \mathrm{C}$ ) in all patients 
Table 3 Main parameters in peripheral blood lymphocyte subpopulations

\begin{tabular}{|c|c|c|c|c|c|c|}
\hline \multirow[t]{2}{*}{ Parameter } & \multicolumn{2}{|l|}{ Before } & \multicolumn{4}{|l|}{ After } \\
\hline & Mean \pm SD & $\begin{array}{l}\text { Minimum- } \\
\text { maximum }\end{array}$ & Me (LQ; UQ) & Mean \pm SD & $\begin{array}{l}\text { Minimum- } \\
\text { maximum }\end{array}$ & Me (LQ; UQ) \\
\hline CD3* & $63.3 \pm 2.1$ & $53-79$ & $62(58 ; 67.5)$ & $71.9 \pm 1.5$ & $64-82$ & $72(67.5 ; 75)$ \\
\hline CD4* & $30.3 \pm 2.3$ & $20-44$ & $33.5(22 ; 35.5)$ & $36.8 \pm 1.8$ & $27-46$ & $36.5(31 ; 42.5)$ \\
\hline CD8* & $24.8 \pm 2.5$ & $19-50$ & $23(19.5 ; 23.5)$ & $32.3 \pm 1.6$ & $26-45$ & $31(28.5 ; 35.5)$ \\
\hline CD3 HLA DR* & $2.3 \pm 0.5$ & $0.7-5.8$ & I.6 (I.I; 3.4) & $4.8 \pm 0.6$ & I.2-9.7 & $4.6(3.9 ; 5.6)$ \\
\hline CDI9* & $27.3 \pm 2.3$ & $13-35$ & $30.5(20 ; 33.5)$ & $16.8 \pm 2.0$ & $7-30$ & $\mid 4.5(|3 ; 2| .5)$ \\
\hline Tregs* & $8.1 \pm 0.6$ & $4.8-10.9$ & $8.0(6.7 ; 10.1)$ & $5.7 \pm 0.5$ & $2.4-8.9$ & $5.3(4.9 ; 6.8)$ \\
\hline NK cells & $5.4 \pm 0.8$ & $0-11$ & $5(4 ; 6)$ & $8.2 \pm 1.0$ & $3-16$ & $7.5(5.5 ; 9.5)$ \\
\hline Cytotoxicity & $35.2 \pm 2.0$ & $24-45$ & $35(29 ; 40.5)$ & $31.3 \pm 2.0$ & $17-40$ & $32.5(27.5 ; 36.5)$ \\
\hline
\end{tabular}

Notes: Immunomonitoring was performed for all 12 patients. Blood samples were taken before the course of heat shock protein 70 and after the last heat shock protein 70 injection. The numbers represent the percentages of the gated lymphocyte populations. No statistical significance was observed for the change in natural killer cell populations and its cytotoxicity $(P>0.05)$. For other lymphocyte subpopulations (marked with $*$ ) statistical significance was $P<0.001$.

Abbreviations: SD, standard deviation; Me, median; LQ, lower quartile; UQ, upper quartile; Tregs, T-regulatory cells; NK, natural killer; CD, cluster of differentiation; HLA, human leukocyte antigen; HLA, human leukocyte antigen.

was 2.5 hours after chaperone injection. At this time, other symptoms appeared (such as nausea, vomiting, and headache). Patients were treated with nonsteroidal anti-inflammatory drugs and all symptoms subsided after 5-6 hours. These symptoms could be due to stimulation of local cytokine production by Hsp70, so although not planned in the pilot study, cytokine levels in cerebrospinal fluid were evaluated $3,6,12,24$, and 48 hours after protein injection in one patient (case 5, Figure 1B). After injection of Hsp70, as expected, there was a transient increase in production of IL-1 $\beta$, IL-1Ra, IL-6, TNF- $\alpha$, and
IFN- $\gamma$ (reaching a peak 3 hours after Hsp70 injection) with a subsequent decrease from 6 hours onwards. Cytokine levels subsided to control levels (before injection of chaperone) within 6 hours.

\section{Administration of Hsp70 decreases immunosuppressive regulatory T-cells}

The role of various immunosuppressive factors has been widely discussed in the literature. Previously, many studies have demonstrated the immunosuppressive role of

Table 4 Main parameters in cytokine levels in peripheral blood

\begin{tabular}{|c|c|c|c|c|c|c|}
\hline \multirow[t]{2}{*}{ Parameter } & \multicolumn{3}{|l|}{ Before } & \multicolumn{3}{|l|}{ After } \\
\hline & Mean \pm SD & $\begin{array}{l}\text { Minimum- } \\
\text { maximum }\end{array}$ & Me (LQ; UQ) & Mean \pm SD & $\begin{array}{l}\text { Minimum- } \\
\text { maximum }\end{array}$ & Me (LQ; UQ) \\
\hline \multicolumn{7}{|l|}{ IL-4 } \\
\hline Serum & $20.5 \pm 7.6$ & $6-103$ & $13(10 ; 18)$ & $6.8 \pm 2.4$ & $\mathrm{I}-24$ & $2.5(2 ; 9.5)$ \\
\hline Spontaneous & $24.3 \pm 7.3$ & $2-67$ & $13(6 ; 47)$ & $9.25 \pm 3.0$ & $\mathrm{I}-34$ & $4.5(2 ; 13.5)$ \\
\hline Induced & $236.6 \pm 29.7$ & $89-421$ & $223.5(160.5 ; 308.5)$ & $110.9 \pm 17.6$ & $23-210$ & 99.5 (67.5; 159) \\
\hline \multicolumn{7}{|l|}{ IL-6 } \\
\hline Serum & $15.8 \pm 3.3$ & $2-39$ & $13(8.5 ; 17)$ & $8 \pm 2.7$ & $2-27$ & $2.5(2 ; 10)$ \\
\hline Spontaneous & $62.2 \pm 18.8$ & $2-248$ & $47(24.5 ; 81)$ & $20.1 \pm 5.5$ & $2-54$ & $15.5(2 ; 34)$ \\
\hline Induced & I,362.8 \pm 273.8 & $378-3,257$ & I,226 (586.5; 2,0I I.5) & $601.6 \pm 102.7$ & $226-1,504$ & $510.5(353.5 ; 734.5)$ \\
\hline \multicolumn{7}{|l|}{ IL-I0 } \\
\hline Serum & $24.3 \pm 3.7$ & $8-46$ & $21(16 ; 33.5)$ & $9.3 \pm 2.7$ & $2-34$ & $7(2.5 ; 10)$ \\
\hline Spontaneous & $40.3 \pm 16.4$ & $2-199$ & $13(8 ; 53.5)$ & $5.6 \pm 1.7$ & $2-23$ & $3(2 ; 7)$ \\
\hline Induced & $241.8 \pm 32.3$ & $125-510$ & 239 (135.5; 299.5) & $110.9 \pm 22.9$ & $29-290$ & 89.5 (5।.5; |46) \\
\hline \multicolumn{7}{|l|}{ IFN- $\gamma$} \\
\hline Serum & $27.8 \pm 5.6$ & $2-70$ & $23(17 ; 35)$ & $63.1 \pm 13.7$ & $20-181$ & $46(30.5 ; 76)$ \\
\hline Spontaneous & $35.8 \pm 10.1$ & $3-133$ & $27(13 ; 47)$ & $158.5 \pm 63.4$ & $36-730$ & $73(54 ; 97.5)$ \\
\hline Induced & $344.2 \pm 111.9$ & $64-1,367$ & $183(14 \mid ; 347.5)$ & $862.9 \pm 283.0$ & $|65-3,64|$ & $458.5(227 ; \mathrm{I}, 180)$ \\
\hline \multicolumn{7}{|l|}{ TNF- $\alpha$} \\
\hline Serum & $8.6 \pm 2.3$ & $2-32$ & $5.5(4.5 ; 10)$ & $23.4 \pm 6.1$ & $6-75$ & I3.5 (7.5; 33) \\
\hline Spontaneous & $8.0 \pm 2.2$ & $2-27$ & $4.5(3 ; 11.5)$ & $37.4 \pm 9.4$ & 4-99 & $31.5(9 ; 59.5)$ \\
\hline Induced & $66.4 \pm 17.5$ & $2-189$ & $38(23 ; 114)$ & $225.3 \pm 47.9$ & $56-564$ & I 60.5 (77; 346.5) \\
\hline
\end{tabular}

Note: For all cytokines, the statistical significance of serum level $(\mathrm{pg} / \mathrm{mL})$ change, spontaneous and induced $\mathrm{production}(\mathrm{pg} / \mathrm{mL}) \mathrm{was} P<0.00 \mathrm{I}$.

Abbreviations: IFN- $\gamma$, interferon gamma; TNF- $\alpha$, tumor necrosis factor alpha; IL, interleukin; SD, standard deviation; Me, median; LQ, lower quartile; UQ, upper quartile. 
regulatory T-cells on tumor-reactive effector T-lymphocytes. In all 12 patients in the present study, a decrease in the relative level of regulatory T-cells (CD4+CD25+Foxp3+) in peripheral blood was observed (from $8.1 \% \pm 0.6 \%$ to $5.7 \% \pm 0.5 \%$, $P<0.001$, Table 3). Further, we assessed for a possible correlation between the decrease in regulatory T-cells and levels of IL-10, and found that serum IL-10 levels abated from $24.3 \pm 3.7 \mathrm{pg} / \mathrm{mL}$ to $9.3 \pm 2.8 \mathrm{pg} / \mathrm{mL}$. Spontaneous IL-10 production also decreased from $40.3 \pm 16.4 \mathrm{pg} / \mathrm{mL}$ to $5.6 \pm 1.7$ $\mathrm{pg} / \mathrm{mL}$; the same phenomenon was observed for induced production by peripheral blood lymphocytes (from $241.8 \pm 32.3$ $\mathrm{pg} / \mathrm{mL}$ to $110.9 \pm 22.9 \mathrm{pg} / \mathrm{mL}$ ). The decrease in regulatory T-cell content in blood after treatment with Hsp70 also corresponded to a decrease in IL-10 production (Table 4).

\section{Hsp70 infusion does not alter the cytolytic activity of natural killer cells}

Relative levels of natural killer cells (CD3-CD16+CD56+) in peripheral blood before and after chaperone administration were analyzed first (Table 3). A slight increase in natural killer cells from $5.4 \% \pm 0.8 \%$ to $8.2 \% \pm 1.0 \%$ was observed, although this was not statistically significant $(P>0.05)$. The cytolytic activity of natural killer cells was then assessed in a cytotoxicity assay (cytotoxic T-lymphocyte test) where effector cells were challenged with K562 cells; no statistically significant increase was found in the cytolytic activity of the natural killer cells (35.2\% $02.0 \%$ before and $31.3 \% \pm 2.0 \%$ after Hsp 70 administration, $P>0.05)$.

\section{Discussion}

The molecular chaperone Hsp70 was recently shown to efficiently stimulate an innate and adaptive antitumor immune response. ${ }^{3,5}$ Direct intratumoral delivery of Hsp70 has been investigated in in vivo experiments, ${ }^{14,15}$ and it was found that the locally delivered chaperone essentially reduces tumor growth via activation of the immune response. ${ }^{15}$ The basic mechanisms of the antitumor immunomodulatory activity of molecular chaperones have been well established since the original discovery of the enhancement of chaperonemediated representation of tumor antigens and initiation of specific anticancer immunity, as well as the recruitment of Hsp70 to the surface of cancer cells, inducing a cytotoxic response by natural killer cells. ${ }^{6,13}$ According to our research, both parts of the immune system are involved in the response induced by Hsp $70 .{ }^{15}$

Local injections of Hsp70 into the resection cavity were well tolerated by patients, with an acceptable toxicity profile.
Previously it was shown that cytokine therapy might have very significant toxicity. High doses of recombinant IL-2 used in patients with renal cancer led to severe complications that significantly limited application of this treatment in the clinic. ${ }^{23,24}$ In the case of local administration of Hsp70, no major side effects beyond grade 3 were observed and the safety profile was comparable with that of other cytokines such as IFN- $\alpha-2 b$ or granulocyte-macrophage colonystimulating factor, which are now used successfully in the treatment of patients with melanoma. ${ }^{23-26}$

Untreated patients with newly diagnosed tumors were enrolled in the present study. In the late stages of cancer progression, there is a certain rate of immunosuppression (via the immunosuppressive activity of tumor-associated macrophages and microglia, tumor-infiltrating lymphocytes, and regulatory T-cells) and exhaustion of tumor-specific CD8+ T-cells, causing immunotherapy to be ineffective. ${ }^{27-31}$ Functional impairment of tumor-associated macrophages and microglia and exhaustion of T-lymphocytes occurs relatively late in the course of tumor growth, potentially providing a window of opportunity for therapeutic strategies directed toward preventing their functional impairment. ${ }^{32}$ Thus, in a Phase III clinical trial of autologous tumor-derived heat shock Hsp gp96 peptide complexes for treatment of patients with stage IV melanoma, the survival rates in patients with the earlier M1a and M1b substages were longer than for patients with substage M1c. ${ }^{8}$

Based on the in vivo data thus far, it was decided to infuse Hsp70 locally in order to provide a high concentration of chaperone inside the resection tumor cavity. It was also proposed that Hsp70 therapy should be performed immediately after tumor debulking. As demonstrated previously, the extent of tumor burden frequently overcomes the magnitude of any immune response induced by vaccination. ${ }^{33}$ In advanced disease, the tumor mass is a harsh environment for immune effectors to enter into and function effectively. It is well known that tumor cells secrete inhibitory cytokines, such as IL-10, transforming growth factor-beta- $\beta$, and prostaglandin E2, that suppress T-cells. ${ }^{34,35}$ After tumor debulking, which may be regarded as a cytoreductive measure, the counterbalance of cytokines could be shifted toward an antitumor response by local application of Hsp70. It was also suggested Hsp70 immunotherapy be performed before conventional treatment, ie, radiotherapy or chemotherapy. Studies have shown that treatment with a tumor vaccine can increase the response to subsequent chemotherapy. ${ }^{36-38}$ The enhanced clinical response to chemotherapy and radiotherapy seen in 
vaccine responders may be due to triggering of pre-existing immunity via treatment-related apoptosis. ${ }^{39-41}$

To assess short-term changes in tumor growth and the response to Hsp70, postoperative MRI was performed within 24 hours of surgery and again 4 weeks after the final Hsp70 injection. Progression of tumor growth was not observed, except in case 12. Moreover, in one case each, a complete response (case 7) and a partial response (case 5) were observed (Figure 1). It is difficult to evaluate the therapeutic potency of Hsp70 given the heterogeneity of this group of patients, but conclusions can be drawn regarding its safety and absence of stimulation of tumor growth. Following their course of Hsp70, the patients received further conventional treatment.

Several explanations have been proposed for the possible anticancer effects of purified Hsp70, and recently, a further explanation for the role of Hsp70 has been suggested. ${ }^{17}$ In previous in vitro experiments using different cell lines, it was shown that exogenous Hsp70 could penetrate cancer cells and induce translocation of intracellular Hsp70 to the cell surface. ${ }^{17,42}$ In our study, elevated expression of membranebound Hsp70 increased the immunorecognition of cancer cells by cytolytic lymphocytes, as confirmed by the cytotoxic T-lymphocyte test. In all 12 patients, elevated levels of Hsp70 were observed in tumor cells. Thus, exogenous Hsp70 introduced intratumorally could penetrate tumor cells and induce translocation of intracellular Hsp70 toward the plasma membrane, enhancing immunorecognition of the tumor cells. Uptake of Hsp70 by tumor cells has been reported previously in models of C6 glioblastoma and B16 melanoma. ${ }^{14,15,43}$ The preferential accumulation of Hsp70 protein in C6 glioblastoma cells could be explained by CD40 receptor-mediated uptake of chaperone..$^{44}$ However, the true importance of this mechanism in overall antitumor immunomodulation by Hsp70 in patients remains debatable.

In the present trial, a shift from cytokines provided by $\mathrm{Th}_{2}$-helper cells (IL-4, IL-6) to cytokines of the $\mathrm{Th}_{1}$-helpermediated response (TNF- $\alpha$, IFN- $\gamma$ ) was observed. These data corresponded to an increase in the overall T-cell subpopulation (including CD4+, CD8+, and activated CD3+HLA DR+) and a concomitant decrease in numbers of B-lymphocytes. Gene expression studies in multiple solid tumor types indicate that upregulation of IFN- $\gamma$ may be associated with improved survival or prognosis. ${ }^{45}$ Investigators have identified a cluster of genes (T-box transcription factor 21, IFN regulatory factor 1, IFN- $\gamma$, CD3, CD8, granulysin, and granzyme B) associated with $\mathrm{Th}_{1}$ immunity and generation of CD8+ cytolytic T-cells. A tumor environment rich in type I cytokines (especially
IFN- $\gamma$ and TNF- $\alpha$ ) would result in increased antigen presentation and generation of cytotoxic T-cells, and would favor tissue destruction. ${ }^{39}$ Moreover, in a study by Donson et al, it was shown that upregulation of immune function-related genes in pediatric patients with ependymoma was associated with a good prognosis and a beneficial immune response. ${ }^{46}$ The present study demonstrates a reversion of the immune system toward a $\mathrm{Th}_{1}$-guided response due to treatment with Hsp70. This may have an impact on control of tumor growth, but further randomized studies are needed. This phenomenon of a Th-polarizing function of Hsp70 is also consistent with results demonstrated by other researchers using various cell lines. ${ }^{9}$ Analysis of cytokine levels in cerebrospinal fluid after injection of Hsp70 showed short-term increases in IFN- $\gamma$ and TNF- $\alpha$ for several hours. Long-term administration of Hsp70 may be needed to maintain elevated levels of these cytokines in the tumor microenvironment, as demonstrated in our recent in vivo study. ${ }^{15}$

Another objective of Hsp70 application is to activate the cytolytic and migratory activities of natural killer cells. ${ }^{13}$ However, while evaluation of natural killer cell levels in peripheral blood showed a slight increase in their numbers, their cytotoxic activity was not altered. In part, this could be explained by the concomitant corticosteroid therapy that the patients received in the preoperative and postoperative periods. On the other hand, activated tumor-reactive natural killer cells could migrate to the tumor site from peripheral blood, and thus could not be detected by routine cytotoxic T-lymphocyte testing. Previously it was demonstrated that although Hsp-based vaccines might not induce generation of cytotoxic natural killer cells, activated natural killer cells are contributing to the antitumor response. ${ }^{47-50}$ Thus, in the study by Zeng et al, it was shown that chaperone vaccination stimulated production of proinflammatory cytokines and chemokines by natural killer cells. ${ }^{50}$

Apart from stimulation of the cell-mediated immune response, a decrease in immunosuppressive regulatory T-cells was observed after administration of Hsp70. Regulatory T-cells function to maintain immune homeostasis and limit acute inflammation. ${ }^{51}$ These cells interfere with T-cell priming and can affect the antitumor function of CD8+ cells via secretion of transforming growth factor-beta and IL-10. ${ }^{52}$ The clinical importance of this phenomenon was demonstrated in the case of ovarian cancer, where it was shown that high levels of regulatory T-cells were associated with decreased survival. ${ }^{53}$ Clinical trials of regulatory T-cell depletion along with antigenspecific vaccination suggest that increases in the induced tumor-specific immune response occurred with reductions in 
the level of regulatory T-cells. ${ }^{54-56}$ Whether this phenomenon of diminished regulatory T-cells as observed in our trial is due to the direct influence of Hsp70 on regulatory T-cells or via cooperation with other cells remains to be explored.

Previously it was reported that positive results on the delayed-type hypersensitivity test might correlate with T-cell antitumor responses. ${ }^{57}$ However, this test was only positive in three patients, including the one patient with a complete response. For precise analysis of specific antitumor-generated responses, other immune assays (ie, ELISPOT) may be needed. Also, an insufficient specific antitumor immune response observed in patients could be an indication to escalate the dose of Hsp70.

Local application of purified recombinant human Hsp70 is feasible and safe, and has an acceptable toxicity profile. We assume that the observed changes in immunologic parameters may correspond to the influence of Hsp70 on the immune system, but might not be relevant to control of tumor growth or total eradication. The present study aimed to determine the feasibility and safety of administration of purified recombinant Hsp70 into the resection cavity in pediatric patients with tumors of the central nervous system. Further randomized clinical trials will determine further the antitumor effect of Hsp70.

\section{Acknowledgments}

We are grateful to Professors David Walker, Martin van den Bent, and Wolfgang Wick for their remarks and comments on the study. We thank Professor Irina S Freidlin for her discussions on immunology. We are indebted to the patients and their families for agreeing to participate in this study, and to the study physicians and nurses for their collaboration. The study was supported by a grant from the Program of Russian Academy of Sciences, "Molecular and Cell Biology", grants from the Russian Fund for Basic Research (10-0401049 and 11-08-00045), and a government grant (14.N08.11.0001, November 20, 2012).

\section{Disclosure}

The authors report no conflicts of interest in this work.

\section{References}

1. Chamberlain MC. Temozolomide: therapeutic limitations in the treatment of adult high-grade gliomas. Expert Rev Neurother. 2010;10: $1537-1544$

2. Heimberger AB, Sampson JH. Immunotherapy coming of age: what will it take to make it standard of care for glioblastoma? Neuro Oncol. 2011;13:3-13.

3. Guzhova IV, Shevtsov MA, Abkin SV, Pankratova KM, Margulis BA. Intracellular and extracellular Hsp70 chaperone as a target for cancer therapy. Int J Hyperthermia. 2013;29:399-408.
4. Srivastava P. Interaction of heat shock proteins with peptides and antigen presenting cells: chaperoning of the innate and adaptive immune responses. Annu Rev Immunol. 2002;20:395-425.

5. Calderwood SK, Theriault JR, Gong J. Message in a bottle: role of the $70-\mathrm{kDa}$ heat shock protein family in anti-tumor immunity. Eur $J$ Immunol. 2005;35:2518-2527.

6. Srivastava PK, Callahan MK, Mauri MM. Treating human cancers with heat shock protein-peptide complexes: the road ahead. Expert Opin Biol Ther. 2009;9:179-186.

7. Wood C, Srivastava P, Bukowski R, et al. An adjuvant autologous therapeutic vaccine (HSPPC-96; vitespen) versus observation alone for patients at high risk of recurrence after nephrectomy for renal cell carcinoma: a multicenter, open-label, randomized phase III trial. Lancet. 2008;372:145-154.

8. Testori A, Richards J, Whitman E, et al. Phase III comparison of vitespen, an autologous tumor-derived heat shock protein gp 96 peptide complex vaccine, with physician's choice of treatment for stage IV melanoma: the C-100-21 Study Group. J Clin Oncol. 2008;26:955-962.

9. Mambula SS, Stevenson MA, Ogawa K, Calderwood SK. Mechanisms for Hsp70 secretion: crossing membranes without a leader. Methods. 2007;43:168-175.

10. Asea A. Initiation of the immune response by extracellular Hsp72: chaperokine activity of Hsp72. Curr Immunol Rev. 2006;2:209-215.

11. Asea A, Rehli M, Kabingu E, et al. Novel signal transduction pathway utilized by extracellular HSP70: role of toll-like receptor (TLR)2 and TLR4. J Biol Chem. 2008;277:15028-15034.

12. Vabulas RM, Ahmad-Nejad P, da Costa C, et al. Endocytosed HSP60s use toll-like receptor 2 (TLR2) and TLR4 to activate the toll/ interleukin-1 receptor signaling pathway in innate immune cells. J Biol Chem. 2001;276:31332-31339.

13. Gastpar R, Gehrmann M, Bausero MA, et al. Heat shock protein 70 surface-positive tumor exosomes stimulate migratory and cytolytic activity of natural killer cells. Cancer Res. 2005;65:5238-5247.

14. Abkin SV, Pankratova KM, Komarova EY, Guzhova IV, Margulis BA. Hsp70 chaperone-based gel composition as a novel immunotherapeutic anti-tumor tool. Cell Stress Chaperones. 2013;18:391-396.

15. Shevtsov MA, Pozdnyakov AV, Mikrina AL, et al. Effective immunotherapy of rat glioblastoma with prolonged intratumoral delivery of exogenous heat shock protein Hsp70. Int J Cancer. Epub 2014 March 19.

16. Guzhova IV, Komarova EY, Pimenova AA, Bakhtin YB, Kaminskaia EV, Margulis BA. [The role of extracellular chaperone Hsp70 in creating antitumor immunity in rat rhabdomyosarcoma RA-2 model]. Vopr Onkol. 2008;54:611-617. Russian.

17. Shevtsov MA, Komarova EY, Meshalkina DA, et al. Exogenously delivered heat shock protein 70 displaces its endogenous analog and sensitizes cancer cells to lymphocytes-mediated cytotoxicity. Oncotarget. Epub 2014 March 22.

18. Guzhova IV, Lazarev VF, Kaznacheeva AV, et al. Novel mechanism of Hsp70 chaperone-mediated prevention of polyglutamine aggregates in a cellular model of Huntington disease. Hum Mol Genet. 2011;20:3953-3963.

19. RF Patent Application. Number 2013128880 from June 25, 2013; number 2013140067 from August 28, 2013.

20. National Cancer Institute, National Institutes of Health, 2003. Common Terminology Criteria for Adverse Events (CTCAE) version 3.0, June 10, 2003 update. Available from: http://ctep.cancer.gov/protocolDevelopment/ electronic_applications/ctc.htm\#ctc_40. Accessed May 15, 2014.

21. Macdonald DR, Cascino TL, Schold SC Jr, Cairncross JG. Response criteria for phase II studies of supratentorial malignant gliomas. J Clin Oncol. 1990;8:1277-1280.

22. Yamanaka R, Homma J, Yajima N, et al. Clinical evaluation of dendritic cell vaccination for patients with recurrent glioma: results of a clinical phase I/II trial. Clin Cancer Res. 2005;11:4160-4167.

23. Fyfe G, Fisher RI, Rosenberg SA, Sznol M, Parkinson DR, Louie AC. Results of treatment of 255 patients with metastatic renal cell carcinoma who received high-dose recombinant interleukin-2 therapy. J Clin Oncol. 1995;13:688-696 
24. Rosenberg SA, Yang YC, Topalian SL, et al. Treatment of 283 consecutive patients with metastatic melanoma or renal cell cancer using high-dose bolus interleukin-2. JAMA. 1994;271:907-913.

25. Gogas H, Ioannovich J, Dafni U, et al. Prognostic significance of autoimmunity during treatment of melanoma with interferon. $N$ Engl J Med. 2006;354:709-718.

26. Kirkwood JM, Strawderman MH, Ernstoff MS, et al. Interferon alfa-2b adjuvant therapy of high-risk resected cutaneous melanoma: The Eastern Cooperative Oncology Group Trial EST 1684. J Clin Oncol. 1996;14: 7-17.

27. Spitler LE, Grossbard ML, Ernstoff MS, et al. Adjuvant therapy of stage III and IV malignant melanoma using granulocyte-macrophage colony-stimulating factor. J Clin Oncol. 2000;18:1614-1621.

28. Watters JJ, Schartner JM, Badie B. Microglia function in brain tumors. J Neurosci Res. 2005;81:447-455.

29. Kim R, Emi M, Tanabe K. Cancer immunosuppression and autoimmune disease: beyond immunosuppressive networks for tumour immunity. Immunology. 2006;119:254-264.

30. Kennedy BC, Maier LM, D'Amico R, et al. Dynamics of central and peripheral immunomodulation in a murine glioma model. $B M C$ Immunol. 2009;10:11.

31. Baitsch L, Baumgaertner P, Devevre E, et al. Exhaustion of tumorspecific CD8+ T cells in metastases from melanoma patients. J Clin Invest. 2011;121:2350-2360.

32. Yi JS, Cox MA, Zajac AJ. T cell exhaustion: characteristics, causes and conversion. Immunology. 2010;129:474-481.

33. Kim PS, Ahmed R. Features of responding T cells in cancer and chronic infection. Curr Opin Immunol. 2010;22:223-230.

34. Geng H, Zhang GM, Xiao H, et al. HSP70 vaccine in combination with gene therapy with plasmid DNA encoding sPD-1 overcomes immune resistance and suppresses the progression of pulmonary metastatic melanoma. Int J Cancer. 2006;118:2657-2664.

35. Marincola F, Jaffee E, Hicklin D, Ferrone S. Escape of human solid tumors from $\mathrm{T}$ cell recognition: molecular mechanisms and functional significance. Adv Immunol. 2000;74:181-273.

36. Disis ML. Immune regulation of cancer. J Clin Oncol. 2010;28: 4531-4538.

37. Arlen P, Gulley JP, Skarupa CL, et al. A randomized phase II study of concurrent docetaxel plus vaccine versus vaccine alone in metastatic androgenindependent prostate cancer. Clin Cancer Res. 2006;12: 1260-1269.

38. Weihrauch M, Ansen S, Jurkiewicz E, et al. Phase I/II combined chemoimmunotherapy with carcinoembryonic antigen-derived HLAA2-restricted CAP-1 peptide and irinotecan, 5-fluorouracil, and leucovorin in patients with primary metastatic colorectal cancer. Clin Cancer Res. 2005;15:5993-6001.

39. Gribben J, Ryan D, Boyajian R, et al. Unexpected association between induction of immunity to the universal tumor antigen CYP1B1 and response to next therapy. Clin Cancer Res. 2005;11:4430-4436.

40. Nowak A, Robinson B, Lake R. Synergy between chemotherapy and immunotherapy in the treatment of established murine solid tumors. Cancer Res. 2003;63:4490-4496.

41. Casares N, Pequignot N, Tesniere A, et al. Caspase-dependent immunogenicity of doxorubicin-induced tumor cell death. J Exp Med. 2006;202: 1691-1701.
42. Shevtsov MA, Guzhova IV, Margulis BA. The hypothesis of a mechanism of anti-tumor action of heat shock protein Hsp70. Available from: http:/ www.cytokines.ru/english/2013/1/Art6.php. Accessed May 21, 2014.

43. Shevtsov MA, Shatik SV, Tokarev AV, et al. [Biodistribution of the recombinant heat shock protein rhHsp70 in intracranial $\mathrm{C} 6$ glioma model in Wistar rats and subcutaneous B16/F10 melanoma in C57BL/6 mice]. Vopr Onkol. 2013;59:78-83. Russian.

44. Shevtsov MA, Yakovleva LY, Nikolaev BP, et al. Tumor targeting using magnetic nanoparticle Hsp70 conjugate in the model of the C6 glioma. Neuro Oncol. 2014;16:38-49.

45. Galon J, Costes A, Sanchez-Cabo F, et al. Type, density, and location of immune cells within human colorectal tumors predict clinical outcome. Science. 2006;313:1960-1964.

46. Donson AM, Birks DK, Barton VN, et al. Immune gene and cell enrichment is associated with a good prognosis in ependymoma. J Immunol. 2009; 183:7428-7440.

47. Crane CA, Han SJ, Ahn B, et al. Individual patient-specific immunity against high-grade glioma after vaccination with autologous tumor derived peptides bound to the $96 \mathrm{KD}$ chaperone protein. Clin Cancer Res. 2013;19:205-214.

48. Pilla L, Patuzzo R, Rivoltini L, et al. A phase II trial of vaccination with autologous, tumor-derived heat shock protein peptide complexes Gp96, in combination with GM-CSF and interferon-alpha in metastatic melanoma patients. Cancer Immunol Immunother. 2006;55:953-968.

49. Massa C, Melani C, Colombo MP. Chaperon and adjuvant activity of Hsp70: different natural killer requirement for cross-priming of chaperoned and bystander antigens. Cancer Res. 2005;65: 7942-7949.

50. Zeng Y, Chen X, Larmonier N, et al. Natural killer cells play a key role in the antitumor immunity generated by chaperone-rich cell lysate vaccination. Int J Cancer. 2006;119:2624-2631.

51. Knutson KL, Disis ML, Salazar LG. CD4 regulatory T cells in human cancer pathogenesis. Cancer Immunol Immunother. 2007;56: 271-285.

52. Li MO, Flavell RA. Contextual regulation of inflammation: a duet by transforming growth factor-beta and interleukin-10. Immunity. 2008;28:468-476.

53. Curiel TJ, Coukos G, Zou L, et al. Specific recruitment of regulatory $\mathrm{T}$ cells in ovarian carcinoma fosters immune privilege and predicts reduced survival. Nat Med. 2004;10:942-949.

54. Dannull J, Su Z, Rizzieri D, et al. Enhancement of vaccine-mediated antitumor immunity in cancer patients after depletion of regulatory T cells. J Clin Invest. 2005;115:3623-3633.

55. Morse MA, Hobeika AC, Osada T, et al. Depletion of human regulatory $\mathrm{T}$ cells specifically enhances antigen-specific immune responses to cancer vaccines. Blood. 2008;112:610-618.

56. Rolle CE, Sengupta S, Lesniak MS. Challenges in clinical design of immunotherapy trials for malignant glioma. Neurosurg Clin $\mathrm{N} \mathrm{Am}$. 2010;21:201-214.

57. Disis ML, Schiffman K, Gooley TA, McNeel DG, Rinn K, Knutson KL. Delayed-type hypersensitivity response is a predictor of peripheral blood T-cell immunity after HER-2/neu peptide immunization. Clin Cancer Res. 2000;6:1347-1350
OncoTargets and Therapy

\section{Publish your work in this journal}

OncoTargets and Therapy is an international, peer-reviewed, open access journal focusing on the pathological basis of all cancers, potential targets for therapy and treatment protocols employed to improve the management of cancer patients. The journal also focuses on the impact of management programs and new therapeutic agents and protocols on

\section{Dovepress}

patient perspectives such as quality of life, adherence and satisfaction. The manuscript management system is completely online and includes a very quick and fair peer-review system, which is all easy to use. Visit http://www.dovepress.com/testimonials.php to read real quotes from published authors. 